\title{
Hereditary angioedema without deficiency of C1 inhibitor: response to therapy
}

\author{
Fabiane Milena Castro Araújo Pimenta*, Vivian Alves Costa, Ana Karolinne Burlamaqui Melo, Aline Lury Aoki, \\ Sandra Mitie Palma, Rosemeire Navickas Constantino-Silva, Neusa Falbo Wandalsen, Anete Grumach
}

From 3rd WAO International Scientific Conference (WISC) 2014

Rio de Janeiro, Brazil. 6-9 December 2014

\section{Background}

Hereditary angioedema (HAE) with normal C1 esterase inhibitor $(\mathrm{C} 1 \mathrm{INH})$ was described for the first time in 2000. It was characterized by subcutaneous, gastrointestinal and laryngeal edema with familial history. Triggering factors are: stress, hormonal factors, trauma and infections. The authors evaluate response to therapy in patients with HAE without C1-INH deficiency.

\section{Methods}

It was analized therapeutical response to hereditary angioedema without deficiency of C1INH. Patients with clinical symptoms compatible with HAE have been included after normal quantitative and functional C1INH levels and positive family history for HAE, independent of factor XII mutation.

\section{Results}

Nineteen patients have been identified (2M:17F; 20-60 years old). The following therapies were oriented: combined contraceptive substitution for progestagen (10/19); treatment with progestagen $(2 / 19)$; tranexamic acid (15/19): $1250 \mathrm{mg}$ (2), $1000 \mathrm{mg}$ (1), 750 (5), $500 \mathrm{mg}$ (4), $250 \mathrm{mg}$ (1); oxandrolon (5/19) (0.5 mg-5mg/day), danazol $200 \mathrm{mg} /$ day (1/19) and combined therapy woth oxandrolon and tranexamic acid in two patients. Icatibant was used in seven patients with clinical improvement. One of them reported increasing frequency of attacks after repeated use of this drug. Two patients received fresh frozen plasma during attacks with clinical improvement.

\section{Conclusions}

HAE without C1-INH deficiency has no established treatment. Clinical improvement was evident with the

Faculty of Medicine ABC, SP, Brazil

(0) 2015 Pimenta et al; licensee BioMed Central Ltd. This is an Open Access article distributed under the terms of the Creative Commons Attribution License (http://creativecommons.org/licenses/by/4.0), which permits unrestricted use, distribution, and reproduction in any medium, provided the original work is properly cited. The Creative Commons Public Domain Dedication waiver (http:// creativecommons.org/publicdomain/zero/1.0/) applies to the data made available in this article, unless otherwise stated. 